\title{
Communication and health: doctor-patient relationship in patients with multimorbidity, an exploratory study
}

\author{
JOSÉ AUGUSTO SIMÕES 1-4, A-G, KATHLEEN PINTO ALBERTO1, A-G , PEDRO AUGUSTO SIMÕES \\ ORCID ID: 0000-0003-2264-7086 ORCID ID: 0000-0001-6829-2271 ORCID ID: 0000-0003-4692-2003 \\ KATIA MAURÍCIO1, D, E , INÊS ROSENDO 1, 2, 4, D-G, LUIZ MIGUEL SANTIAGO1, 2, 5, D-G \\ ORCID ID: 0000-0002-9479-4600 ORCID ID: 0000-0001-8838-6021 ORCID ID: 0000-0002-9343-2827 \\ ${ }^{1}$ Faculty of Medicine, University of Coimbra, Portugal \\ ${ }^{2}$ University Clinic of General and Family Medicine, Faculty of Medicine, University of Coimbra, Portugal \\ ${ }^{3}$ Faculty of Health Sciences, University of Beira Interior, Covilhã, Portugal \\ ${ }^{4}$ CINTESIS - Centre for Research in Health Technologies and Service, Oporto, Portugal \\ ${ }^{5}$ CEISUC - Centre for Health Studies and Investigation of the University of Coimbra, Portugal
}

A - Study Design, B - Data Collection, C - Statistical Analysis, D - Data Interpretation, E - Manuscript Preparation, F - Literature Search, G - Funds Collection

Summary Background. With the increase of average life expectancy and the aging of the population, an increase in multimorbidity has also been observed. Effective communication in the doctor-patient relationship is directly related to the promotion of health of patients with multimorbidity. One of the fundamental foundations of this doctor-patient relationship is the physician's ability to establish an empathic relationship with the patient.

Objectives. The objective of this study is to compare Family Medicine consultations and Hospital consultations in terms of empathic communication and the doctor-patient relationship in patients with multimorbidity.

Material and methods. An exploratory observational cross-sectional study was carried out using elderly people with multimorbidity and applying the JSPE scale. Statistical analysis was performed using descriptive statistics and the non-parametric Mann-Whitney U test.

Results. For all questions on the JSPE scale, the family physician scored higher than the hospital physician. Between the specialties, statistically significant differences were obtained.

Conclusions. The differences between Family Medicine consultations and Hospital consultations has an impact on the results of the medical empathy felt by the patients. Other studies demonstrate the importance of empathy in the doctor-patient relationship, and in this study, we concluded that there is a greater degree of empathy felt by the patients in Family Medicine consultations compared to the lower degree of empathy felt by the patients in Hospital consultations.

Key words: communication, multimorbidity, patients, empathy, aged.

Simões JA, Alberto KP, Simões PA, Maurício K, Rosendo I, Santiago LM. Communication and health: doctor-patient relationship in patients with multimorbidity, an exploratory study. Fam Med Prim Care Rev 2019; 21(4): 377-380, doi: https://doi.org/10.5114/ fmpcr.2019.90169.

\section{Background}

With the increase of average life expectancy and the aging of the population, an increase in multimorbidity has also been observed [1]. Multimorbidity is defined as a combination of a chronic disease with at least one other disease (chronic or acute), or with a biopsychosocial factor (associated or not), or with a somatic risk factor [2]. Multimorbidity affects about a third of the Portuguese population [1], and its prevalence in the Portuguese population has a great impact on the National Health System.

Consultations between patients and physicians are the primary activity of medical care specialists. More attention is being paid to patients' opinions about their care and consultation, as well as the development of a more holistic and patient-centred approach. Empathy is considered a basic component of all medical relationships and a key factor in the definition of quality of patient care. Empathy has been shown to improve the doctor-patient relationship and improve patient empowerment and patient and physician satisfaction during clinical encounters [3].

Health communication and the doctor-patient relationship are the means by which the physician can convey the intended information to the patient. For the patient to understand his state of health, it is necessary that this message be correctly interpreted so that they can follow the indications provided by the doctor and adopt the behaviours necessary to optimise their state of health [4]. One of the fundamental bases of this doctor-patient relationship is the physician's ability to establish an empathic relationship with the patient [4]. Empathy is characterised as the ability to perceive the situation, perspective and feelings of the patient and communicate this understanding to them, making it a fundamental instrument for optimising a patient-centred clinical interview $[4,5]$. Empathy is not an innate clinical aptitude; it requires concentration and training by the physician in decoding non-verbal language and a patient's expressiveness [6]. The use of open questions and expressions that validate the patient's feelings allows for a more open and fluent discussion, enabling the patient to talk more freely about their problems [7]. What the patients gains from the consultation is the ability to be able to understand and deal with their illness [8], making it essential that the technical terms used by the physician are appropriate and understood by the patient. Patient satisfaction with the information provided about their disease and morbidity is indicative of the quality of the infor- 
mation and its relation to physical, psychological and overall morbidity [9]. Effective communication in the doctor-patient relationship is directly related to the promotion of a patient's health [10] and is especially important in patients with multi-morbidities, representing $72 \%$ of the patients attending Primary Health Care in Portugal [11].

\section{Objectives}

The objective of this study was to compare Family Medicine consultations and Hospital consultations in terms of empathic communication and doctor=patient relationship in patients with multimorbidity.

\section{Material and methods}

\section{Sample and selection of participants}

The research consisted of a cross-sectional exploratory observational study using a convenience sample of people with multimorbidity contacted outside health units (health centre and hospital), in a social community centre, who accepted participation in the study questionnaire.

The study was carried out in a rural population of the municipality of Montemor-o-Velho, Portugal, in a social community centre attended by 45 elderly people, aged between 50 and 90 years. The criteria for inclusion in the study were to have multimorbidity and those who had at least one visit the previous year with a family physician and a hospital physician.

\section{Data collection}

The investigations were carried out by the researcher in a relaxed atmosphere and ensured the anonymity of the individuals, respecting the ethical principles of the Declaration of Helsinki. The purpose of the study was explained to participants, with a brief introduction summarising the objectives of the study and asking for their consent for their anonymous participation in the study. The language was adapted according to the level of literacy of the person interviewed, minimising unreliable answers by misunderstanding of the questions. Since this was a study in a population of advanced age and low educational level, this adjustment of the language utilised was especially important.

All data for the study was collected through an individual interview, and each interview lasted about one hour.

First, a questionnaire was applied regarding the characterisation of the population, where the gender, age, marital status, schooling, profession, household and chronic pathologies were questioned.

After the initial questionnaire was applied, the Jefferson Scale of Physician Empathy (the JSPE scale) was used to assess the patient's perception of medical empathy [12]. There are several studies on the validity of this instrument in the evaluation of empathy [13-15], and this scale was validated for use in Portugal in 2015 [16].

\section{Data analysis}

Statistical analysis of the data was performed using SPSS (Statistical Package for the Social Sciences) software version 24.0 for Windows (SPSS Inc, Chicago, IL, USA).

A descriptive analysis of the variables was carried out through frequency tables. The non-parametric Mann-Whitney $U$ test was used to compare the results of the JSPE scale of Family Medicine consultations with the results of the JSPE scale of Hospital consultations.

\section{Results}

The attendees of the social community centre were 45 elderly individuals, of whom $\mathbf{3 0}$ met the criteria for inclusion in the study.

The general characterisation of the sample is shown in Table 1. Of the 30 participants, $46.7 \%$ were female, and $53.3 \%$ were male. The average age of participants was 70.8 years, the minimum age being 52 years and the maximum 89 years. The majority were married $(76.7 \%)$, retired $(70 \%)$, live together $(70 \%)$ and had schooling equal to or lower than the $4^{\text {th }}$ grade (83.3\%). The most frequent chronic pathologies in the sample were metabolic diseases (90\%), cardiovascular pathology (70\%) and musculoskeletal pathology (50\%).

\begin{tabular}{|c|c|c|}
\hline & $n(30)$ & $\%$ \\
\hline $\begin{array}{l}\text { Gender } \\
\text { female } \\
\text { male }\end{array}$ & $\begin{array}{l}14 \\
16 \\
\end{array}$ & $\begin{array}{l}46.7 \\
53.3 \\
\end{array}$ \\
\hline $\begin{array}{l}\text { Average age (years) } \\
\quad<70.8 \\
>70.8\end{array}$ & $\begin{array}{l}15 \\
15 \\
\end{array}$ & $\begin{array}{l}50 \\
50 \\
\end{array}$ \\
\hline $\begin{array}{l}\text { Marital status } \\
\text { single } \\
\text { married } \\
\text { widowed } \\
\end{array}$ & $\begin{array}{l}2 \\
23 \\
5 \\
\end{array}$ & $\begin{array}{l}6.7 \\
76.7 \\
16.7 \\
\end{array}$ \\
\hline $\begin{array}{l}\text { Profession } \\
\text { employed } \\
\text { unemployed } \\
\text { retired } \\
\end{array}$ & $\begin{array}{l}9 \\
0 \\
21\end{array}$ & $\begin{array}{l}30 \\
0 \\
70 \\
\end{array}$ \\
\hline $\begin{array}{l}\text { Family status } \\
\text { lives alone } \\
\text { lives with someone }\end{array}$ & $\begin{array}{l}9 \\
21 \\
\end{array}$ & $\begin{array}{l}30 \\
70 \\
\end{array}$ \\
\hline $\begin{array}{l}\text { Schooling } \\
<4^{\text {th }} \text { grade } \\
4^{\text {th }} \text { grade } \\
6^{\text {th }} \text { grade } \\
9^{\text {th }} \text { grade }\end{array}$ & $\begin{array}{l}9 \\
16 \\
1 \\
4 \\
\end{array}$ & $\begin{array}{l}30 \\
53.3 \\
3.3 \\
13.3 \\
\end{array}$ \\
\hline $\begin{array}{l}\text { Chronic pathologies } \\
\text { cardiovascular pathology } \\
\text { musculoskeletal pathology } \\
\text { neurodegenerative pathology } \\
\text { oncology pathology } \\
\text { metabolic diseases }\end{array}$ & $\begin{array}{l}21 \\
15 \\
3 \\
2 \\
27\end{array}$ & $\begin{array}{l}70 \\
50 \\
10 \\
6.7 \\
90 \\
\end{array}$ \\
\hline
\end{tabular}

Table 2 shows the average results for each question on the JSPE scale for Family Medicine consultations and for Hospital consultations. The scale has 5 questions and each answer ranges from 1 to 7 , with 1 being "totally disagree" and 7 "totally agree". The closer to 7, the more empathic the physician is considered to be, and the closer to 1 , the colder and more distant the physician is considered to be.

In the mean of the answers of the JSPE scale for Family Medicine consultations, high scores were obtained for all questions, with question 3 being the highest score (6.2) and question 4 being scored 5.6, with only a difference of 0.6 between the means of the highest score and the lowest score.

In the mean of responses from the JSPE scale for Hospital Specialties, there was greater heterogeneity between the questions. The highest value (5.2) was obtained in question 1 , and the lowest value (3.1) in question 2 , with a significant difference of 2.1 between the means of the highest score and the lowest score.

Since our data did not follow a normal distribution utilising the Kolmogorov-Smirnov test, the non-parametric Mann-Whit- 
ney $U$ test, with a significance level of 0.05 , was used for the comparison between Family Medicine and Hospital Specialties, and statistically significant differences were found for questions 2, 3, 4 and 5. For question 1, there was no statistical significance.

\begin{tabular}{|l|l|l|l|}
\hline Table 2. JSPE Scale & $\begin{array}{l}\text { Family } \\
\text { Medicine }\end{array}$ & $\begin{array}{l}\text { Hospital } \\
\text { Specialties }\end{array}$ & $p$ \\
\hline $\begin{array}{l}\text { They can understand things } \\
\text { from my perspective (see } \\
\text { things as I see them) }\end{array}$ & 5.9 & 5.2 & 0.071 \\
\hline $\begin{array}{l}\text { They ask about what is hap- } \\
\text { pening in my daily life }\end{array}$ & 5.9 & 3.1 & $<0.001$ \\
\hline $\begin{array}{l}\text { They seem worried about } \\
\text { me and my family }\end{array}$ & 6.2 & 3.2 & $<0.001$ \\
\hline $\begin{array}{l}\text { They understand my emo- } \\
\text { tions, feelings and concerns }\end{array}$ & 5.6 & 4.5 & 0.0315 \\
\hline The doctor understands me & 6.1 & 5 & 0.0145 \\
\hline
\end{tabular}

\section{Discussion}

The objective of this study is to compare Family Medicine consultations and Hospital consultations in terms of empathic communication and doctor-patient relationship in patients with multimorbidity. Patients with multimorbidity attend primary care in Portugal [11] and often require specialised care. In order to obtain specialised care, family physicians need to refer these patients to hospital physicians. This joint work between different specialties is essential for the optimisation of the patient's health and quality of life [17].

Medical empathy was assessed through the JSPE scale for family physicians and hospital physicians, and the differences were compared. For all five questions on the JSPE scale, the family physician scored higher. In studying the difference between the two, no statistically significant differences were obtained in the statement They can understand things from my perspective, demonstrating that the patient in both settings feels that the doctor understands what they are trying to convey. In the statements They understand my emotions, feelings and concerns and The doctor understands me, there were statistically significant albeit small differences between family physicians and hospital physicians. The most statistically significant differences were in the questions They ask about what is happening in my daily life and They seem worried about me and my family. These differences may be because these statements are more objective, not depending so much on the patient's perception. If the hospital specialist does not ask what is going on in the patient's life or about his family, the patient cannot score them, while the other questions, being more subjective, depend more on the patient's perception of the physician.

In the present study, we verified that empathy becomes essential in medical communication, allowing a relationship of trust with the patient so that they feel at ease to expose their doubts and fears. With the establishment of this link, the doctor can answer questions more easily. With this gain of capacity and knowledge by the patient, they adhere better to their treatments. Empathy alone does not improve patients' adherence to treatments, and it is necessary for them to understand their illness and to know how to deal with it; however, if the patient does not feel the doctor's empathy, it will make it difficult to communicate their doubts and also gain the ability to cope with their illness [18].

The increase in patients with multimorbidity and the consequent overload of health care services makes it essential to optimise communication in the doctor-patient relationship and in patient-centred consultation for more effective management of these patients [19].

Patients' perceptions about the empathy of physicians are of fundamental importance in the training of physicians in medical consultations in low and high deprivation settings. Training is lower in patients with multimorbidity (of two or more health conditions) and those who consult about a longstanding problem. In deprived areas, as rural areas, psychological suffering has an additional negative influence. Ways to support and improve physician empathy can be crucial to improving patient empowerment, especially in areas of high deprivation, where the burden of multimorbidity, mental illness and health problems is greater [20].

\section{Limitations of the study}

One limitation of the study was the small number of the sample, since only 30 surveys were collected.

\section{Conclusions}

The differences between Family Medicine consultations and Hospital consultations has an impact on the results of the medical empathy felt by patients. Other studies demonstrate the importance of empathy in the doctor-patient relationship, and in this study, we concluded that there is a greater degree of empathy felt by the patients in Family Medicine consultations compared to the lower degree of empathy felt by the patients in Hospital consultations.

Source of funding: This work was funded from the authors' own resources.

Conflicts of interest: The authors declare no conflicts of interest.

\section{References}

1. Romana GQ, Kislaya I, Salvador MR, et al. Multimorbilidade em Portugal: Dados do Primeiro Inquérito Nacional de Saúde com Exame Físico. Acta Med Port 2019; 32(1): 30-37, doi: 10.20344/amp.11227 (in Portuguese).

2. Prazeres F, Santiago LM, Simões JA. Defining multimorbidity. From english to portuguese using a Delphi Technique. BioMed Res Int 2015, doi: 10.1155/2015/965025.

3. Mercer SW, Maxwell M, Heaney D, et al. The consultation and relational empathy (CARE) measure: development and preliminary validation and reliability of an empathy-based consultation process measure. Fam Pract 2004; 21(6): 699-705.

4. Ramos V. A consulta em 7 passos. Execução e análise crítica de consultas em Medicina Geral e Familiar. Rev Port Clin Geral 2009; 25(2): 208-220, doi: 10.32385/rpmgf.v25i2.10609 (in Portuguese).

5. Charon R. Narrative medicine: a model for empathy, reflection, profession, and trust. JAMA 2001; 286(15): $1897-1902$.

6. Pollak KI, Alexander SC, Tulsky JA, et al. Physician empathy and listening: associations with patient satisfaction and autonomy. $J$ Am Board Fam Med 2011; 24(6): 665-672, doi: 10.3122/jabfm.2011.06.110025.

7. American College of Obstetricians and Gynecologists Committee on Ethics. Committee Opinion No. 480: Empathy in women's health care. Obstet Gynecol 2011; 117(3): 756-761, doi: 10.1097/AOG.0b013e3182147865.

8. Reis AF, Santiago LM, Botas P. Medicina Centrada no Paciente e Capacitação do Consulente em Medicina Geral e Familiar. Rev ADSO 2015; 3(5): 19-32, doi: 10.35323/revadso.35201530 (in Portuguese). 
9. Martins, JC. Patients' satisfaction with information on disease and morbidity. Rev Latino-Am Enfermagem 2009; 17(3): 335-340, doi: 10.1590/S0104-11692009000300009.

10. Stewart MA. Effective physician-patient communication and health outcomes: a review. CMAJ 1995; 152(9): 1423-1433.

11. Prazeres F, Santiago LM. Prevalence of multimorbidity in the adult population attending primary care in Portugal: a cross-sectional study. BMJ Open 2015; 5(9), doi: 10.1136/bmjopen-2015-009287.

12. Kane GC, Gotto JL, Mangione S, et al. Jefferson Scale of Patient's Perceptions of Physician Empathy: preliminary psychometric data. Croat Med J 2007; 48(1): 81-86

13. Hemmerdinger JM, Stoddart SDR, Lilford RJ. A systematic review of tests of empathy in medicine. BMC Med Educ 2007; 7: 24, doi: 10.1186/1472-6920-7-24.

14. Hojat M, Louis DZ, Maxwell K, et al. Patient perceptions of physician empathy, satisfaction with physician, interpersonal trust, and compliance. Int J Med Educ 2010; 1: 83-87, doi: 10.5116/ijme.4d00.b701.

15. Glaser KM, Markham FW, Adler HM, et al. Relationships between scores on the Jefferson Scale of physician empathy, patient perceptions of physician empathy, and humanistic approaches to patient care: a validity study. Med Sci Monit 2007; 13(7): CR291-4.

16. Domingues AC, Santiago LM, Saraiva CB. A empatia na consulta e a capacitação dos consulentes [dissertation - Master's Tesis; 10316/31101]. Coimbra University; 2015 (in Portuguese).

17. Tieman J, Mitchell G, Shelby-James T, et al. Integration, coordination and multidisciplinary care: what can these approaches offer to Australian primary health care? Aust J Prim Health 2007; 13(2): 56-65.

18. Partida Y. Language barriers and the patient encounter. Virtual Mentor 2007; 9(8): 566-571, doi: 10.1001/virtualmentor.2007.9.8.ms oc1-0708.

19. Saha S, Beach MC. The impact of patient-centered communication on patients' decision making and evaluations of physicians: a randomized study using video vignettes. Patient Educ Couns 2011; 84(3): 386-392, doi: 10.1016/j.pec.2011.04.023.

20. Mercer SW, Jani BD, Maxwell M, et al. Patient enablement requires physician empathy: a cross-sectional study general practice consultations in areas of high and low socioeconomic deprivation in Scotland. BMC Fam Pract 2012; 13: 6, doi: 10.1186/1471-2296-13-6.

Tables: 2

Figures: 0

References: 20

Received: 6.05.2019

Reviewed: 11.05 .2019

Accepted: 5.07.2019

Address for correspondence:

José Augusto Simões, MD, PhD

University Clinic of General and Family Medicine

Faculty of Medicine

University of Coimbra

Pólo III - Ciências da Saúde, Subunidade 3

Azinhaga de Santa Comba, Celas

3000-548 Coimbra

Portugal

Tel.: +351924406

E-mail: jars@uc.pt 